\title{
Female Genital Tract Infection Caused by Streptococcus Pneumoniae: Case Report
}

\author{
Hamdoun $\mathbf{M}^{1,4,5 *}$, Hannachi $\mathbf{H}^{1,4,5}$, Braham $\mathbf{M}^{2,4,5}$, Kacem $\mathbf{K}^{3,4,5}$, Zhioua $\mathrm{F}^{2,4,5}$, Zhioua $\mathbf{A}^{3,4,5}$ and Bahri $\mathbf{0}^{1,4,5}$ \\ ${ }^{1}$ Laboratory of Biochemistry and Microbiology, Aziza Othmana Hospital, Tunisia
}

${ }^{2}$ Department of Obstetrics and Gynecology, Aziza Othmana Hospital, Tunisia

${ }^{3}$ Assisted Reproductive Technologies Center, Aziza Othmana Hospital, Tunisia

${ }^{4}$ LR16SP01 Laboratory Research, Tunisia

${ }^{5}$ Faculty of Medicine of Tunis, Tunis El Manar University, Tunisia

Submission: June 12, 2018; Published: October 15, 2018

*Corresponding author: Manel Hamdoun, Laboratory of biochemistry and microbiology, Aziza Othmana Hospital, 1008, La Kasbah, Tunis, Tunisia, Tel: +21694266561; Email: hamdoun.zahmoul@gmail.com

\begin{abstract}
Streptococcus pneumoniae is an important respiratory pathogen and can also cause meningitis and bacteremia. It is very rarely responsible of genital tract infections. We report the case of a pelvic inflammatory disease due to S. pneumonia in a menopaused woman with no predisposing factors. Bacteriological diagnosis was obtained using endocervical and vaginal samples. The patient recovered well without consequences with antibiotic therapy.
\end{abstract}

Keywords: Pelvic inflammatory disease; Streptococcus pneumonia; Vaginal colonization

\section{Introduction}

Streptococcus pneumoniae is a commensal of the upper respiratory tract.It is a major cause of communityacquired pneumonia, bacteremia, meningitis, otitis, sinusitis, and carries a high burden of morbidity andmortality [1]. Furthermore, it is a less frequent cause of endocarditis, septic arthritis, and peritonitis [2].Uncommon colonization sites may cause rare clinical manifestations. We report the case of a pelvicinflammatory disease due to S.pneumoniain a menopaused woman with no predisposing factors.

\section{Case Report}

A 57-year-old woman with history of type 2 diabetes and high blood pressure was admitted to our hospital complaining of hypogastric pain and sustained fever. She was multiparous (4 children) and have had menopause since, one year and a half. The general physical exam found a fever of $38.8^{\circ} \mathrm{C}$ and tenderness in the right lower abdominal quadrant. Pelvic examination showed abundant green vaginal discharge and painful mobilization of the uterus. Vaginal and endocervical samples were then collected. The patient was otherwise normotensive with a pulse rate of 80bpm. On admission, blood tests showed hyperleucocytosis $(15000 / \mathrm{mm} 3)$ and $\mathrm{C}$ reactive protein of $66 \mathrm{mg} / \mathrm{l}$. Abdominal and pelvic ultrasound found a right juxta-ovarian collection with 2X2 $\mathrm{cm}$ dimensions. Intravenous antibiotic treatment was initiated (cirprofloxacin and amoxicillin+clavulanic acid). The patient had improved within $48 \mathrm{~h}$ of antibiotherapy and was discharged at day five with oral treatment for 14 days. Bacteriological samples showed numerous polynuclear cells and the culture turned out positive after $48 \mathrm{~h}$ incubation with many colonies of Streptococcus pneumoniae. The colonies on blood agar were very mucoid and surrounded by an a hemolysis zone (Figure 1). Antibiogram showed sensitivity to penicillin and norfloxacin. Serotyping could not be performed.

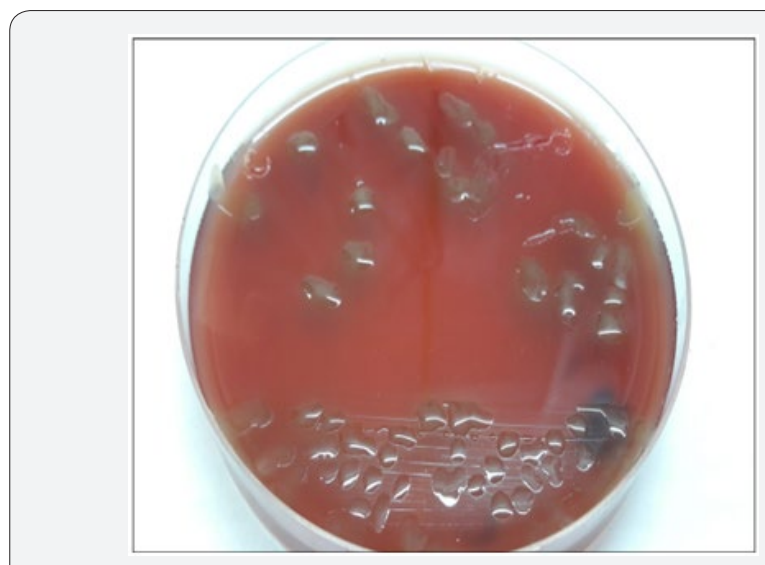

Figure 1: colonies of Streptococcus pneumoniae on blood agar. 


\section{Global Journal of Reproductive Medicine}

\section{Discussion}

Pelvic inflammatory disease is a rare manifestation of pneumococcal infections. Although S.pneumoniae typically colonizes the upper respiratory tract, it can be part of the commensal flora of the female genital tract [3]. Prevalence of vaginal colonization with S.pneumoniae is unknown; Pneumococci were not isolated from normal vaginal flora in two ancient studies with a total of 294 gynecologic and 52 obstetric patients [4,5]. Darbas and Boyer reported seven isolates from 1064 vaginal secretions $(0.75 \%)$, one isolate from 265 placentas, and one isolate from 40 intrauterine contraceptive devices (IUDs) that had been removed [6]. Changes in sexual practice (i.e., increased orogenital sex) and improved isolation techniques have been suggested as potential cause for the detection of S.pneumoniae in vaginal specimens [7]. However, although a history of receptive oral-anal sex was found to be associated with unstable vaginal flora and bacterial vaginosis, an association between sexual behavior and recovery of S.pneumoniae in vaginal specimens has not been reported [2]. Other transmission modes of pneumococci to the vagina could be a spread from the respiratory tract by hand contamination or hematogenous route [8].

Pneumococcal infection of the internal genital tract may give rise to endometritis, salpingitis, pelvic inflammatory disease, and abscesses and may be complicated by diffuse peritonitis. The symptoms and signs of these infections are in general not specific and rarely allow the clinician to suspect particular causative agents. Westh et al.[9]reported nine cases of pneumococcal infection of the female genital tract along with seven cases of pneumococcal bartholinitis. In their review, they found reports of 27 cases published between 1938 and 1988. One or more predisposing factors were discerned in most of the patients, mainly the use of intrauterine contraceptive devices (IUD) or changes secondary to the postpartum or postabortion period. The authors also pointed out the fact that pneumococcal genital infection was more common in the preantibiotic era than today, and the rate of lethality was high. During the last decade, more recent cases were reported by Gardien et al. [10], and Lemonye et al. [2]. When the infections occur, the route could be primary resident flora, gastrointestinal tract, lymphatics, or blood stream [11]. When S.pneumoniae is present in the adult vagina it can infects Bartholin's glands [9]. From the vagina it can also ascend to the internal genitals; this type of infection is increased by the predisposing factors (IUD, postpartum state, instrumentation of the uterine cavity). No such factors were observed in our case.
Serotypes 1 and 3 are among the most incriminated serotypes in female genital infections [10]. The importance of these two serotypes in complicated female genital infections had previously been emphasized and their particular affinity for the genital tract suggested [12]. Genital infections can be handled without consequences when diagnosed early [10]. Their treatment is facilitated by the high proportion of penicillin-sensitive strains (high frequency of serotypes 1 and 3 which are hardly resistant to penicillin) as was the case of our patient.

\section{References}

1. Musher DM (1992) Infections caused by Streptococcus pneumoniae: clinical spectrum, pathogenesis, immunity, and treatment. Clin Inf Dis 14: 801-807.

2. Lemoyne S, Van Leemput J, Smet D, Desmedt E, Devos H, et al. (2008) Pelvic inflammatory disease due to Streptococcus pneumoniae: a usual pathogen at an unusual place. Acta Clinica Belgica 63(6): 398-401.

3. Larsen B, Monif GR (2001) Understanding the bacterial flora of the female genital tract. Clin Infect Dis 32(4): e69-77.

4. Neary MP, Allen J, Okubadejo OA, Payne DJH (1973) Preoperative vaginal bacteria and postoperative infections in gynaecological patients. Lancet 2: 1291-1294.

5. Tashjian JH, Coulam CB, Washington JA (1976) Vaginal flora in asymptomatic women. Mayo Clin Proc 51(9): 557-561.

6. Darbás H, Boyer G (1987) Isolation of Streptococcus pneumoniae from genital samples. Discussion of its pathogenic role. Pathol Biol 35: 177180.

7. McDonald LC, Bryant K, Snyder J (2003) Peripartum transmission of penicillin-resistant Streptococcus pneumoniae. J Clin Microbiol 41(5): 2258-2260.

8. Bucher A, Müller F (2002) Spectrum of abdominal and pelvic infections caused by pneumococci in previously healthy adult women. Eur J Clin Microbiol Infect Dis 21(6): 474-477.

9. Westh H, Skibsted L, Korner B (1990) Streptococcus pneumoniae infections of the female genital tract and in the newborn child. Rev Infect Dis 12(3): 416-422.

10. Gardien E (2001) À propos d'un cas de salpingite à Streptococcus pneumoniae, épidemiologie des infections génitales de la femme à pneumocoque. Pathol Biol 49(2): 124-127.

11. Setty CR (1993) Isolation of Streptococcus pneumoniae from female genital tract. Ann Saudi Med 13(4): 381-382.

12. Sirotnak AP, Eppes SC, Klein JD (1996) Tuboovarian abscess and peritonitis caused by Streptococcus pneumoniae serotype 1 in young girls. Clin Infect Dis 22(6): 993-996. 
(C) (1) This work is licensed under Creative

(C) BY DOI: $10.19080 /$ GJORM.2018.06.555684

\begin{tabular}{l} 
Your next submission with Juniper Publishers \\
will reach you the below assets \\
- Quality Editorial service \\
- Swift Peer Review \\
- Reprints availability \\
- E-prints Service \\
- Manuscript Podcast for convenient understanding \\
- Global attainment for your research \\
- Manuscript accessibility in different formats \\
( Pdf, E-pub, Full Text, Audio) \\
- Unceasing customer service \\
Track the below URL for one-step submission \\
https://juniperpublishers.com/online-submission.php \\
\hline
\end{tabular}

